\title{
Microbial Synthesis and Flocculation Performance of Poly ( $\gamma$-glutamic Acid)
}

\author{
Yanli Zhang \\ Shandong Academy of Governance, Jinan 250014, China
}

\begin{abstract}
Monosodium glutamate wastewater (MSGW) is a nutrient cultivation medium for microorganism cultivation because it contains abundant nutrient. The research focused on the cultivation of $B$. subtilis 168 with MSGW to produce poly $(\gamma$ glutamic acid). The optimal cultivation conditions for the production of poly $(\gamma$-glutamic acid) by $B$. subtilis 168 were obtained. Simultaneously, the flocculation performances of culture supernatant and crude $\gamma$-PGA were also investigated. Turbidity and active red removal efficiency of crude $\gamma$-PGA was about $80 \%$ and $55 \%$, respectively.
\end{abstract}

Keywords—microbial synthesis; flocculation performance; poly (y-glutamic acid)

\section{INTRODUCTION}

Biopolymers are considered as a potential alternative to conventional polymers because of their high efficiency, biodegradability, and non-secondary pollution. Recently, many researchers recognized that biopolymers were potential flocculant for water and wastewater treatment ${ }^{[1]}$. Poly $(\gamma-$ glutamic acid) ( $\gamma$-PGA) is such a water-soluble, anionic, biodegradable, and edible biopolymer produced by microorganisms, which has a single strain structure formed by 5000-10,000 repeating units of D- and L-glutamic acids connected by amide linkages between $\alpha$-amino and $\gamma$-carboxyl groups $^{[2,3]}$. Gamma PGA and its derivatives can be used in a wide range of products such as food stuff, bitterness relieving agent, cosmetics, thickener, medicines, humectant, sustained released material, cryoprotectant, drug carrier, biological adhesive, biopolymer flocculants and heavy metal absorber ${ }^{[4]}$. Wide range of application potential of $\gamma$-PGA has drawn attention of many researchers to its production. The strain Bacillus subtilis F-2-01 isolated from a soil sample was found to produce $\gamma$-PGA with a molecular weight of about $1.0 \times 10^{6}$ $[5,6]$. Furthermore, flocculating activity of cross-linked $\gamma$-PGA against Kaolin suspension and polluted water collected from rivers and ponds was investigated ${ }^{[7]}$. Glucose was reported to support $\gamma$-PGA production in most of the $\gamma$-PGA producing strains ${ }^{[8]}$. However, high production cost is a major traditional bottleneck of $\gamma$-PGA application in water and wastewater treatment ${ }^{[9]}$. Therefore, it is of great significance to decrease the $\gamma$-PGA production cost using cheap cultivation substrates.

Monosodium glutamate (MSG), a sodium salt of Lglutamic acid, is used as flavor enhancer for foods. Monosodium glutamate wastewater (MSGW) has high levels of COD, BOD, sulfate, ammonium-N, and a low $\mathrm{pH}$ of 2-3 after the extraction of MSG ${ }^{[10]}$. The MSGW treatment needs expensive cost, which is a major obstacle for the development of MSG production. Despite several strategies having been developed to treat MSGW, the economical and efficient treatment of MSGW is still challenging [11]. In this study, we want to try using the MSGW as a culture medium for $B$. subtilis 168 to produce $\gamma$-PGA. The purpose of this research was to determine the optimal cultivation conditions for $B$. subtilis 168 to produce $\gamma$-PGA using MSGW as a culture medium, which provide a method for economical production of $\gamma$-PGA as well as a nutrient resource utilization of MSGW. Moreover, the flocculation performances of culture supernatant and crude $\gamma$-PGA were also investigated.

\section{METHODS}

\section{A. Monosodium Glutamate Wastewater (MSGW)}

The MSGW used in this study was obtained from a monosodium glutamate factory of Shandong province. The MSGW was the residual fermentation broth after glutamate extraction which presented a brown-black acidic liquid.

\section{B. Microorganism and Cultivation Conditions}

The B. subtilis 168 used in this study was graciously provided by Professor Li Li, School of Environmental Science and Engineering, Shandong University. The strain $B$. subtilis 168 was cultured on LB agar plate (containing $10 \mathrm{~g} \mathrm{~L}^{-1}$ peptone, $5 \mathrm{~g} \mathrm{~L}^{-1}$ yeast extract, $10 \mathrm{~g} \mathrm{~L}^{-1} \mathrm{NaCl}$ and $20 \mathrm{~g} \mathrm{~L}^{-1}$ agar) for $24 \mathrm{~h}$ at $37 \pm 0.5^{\circ} \mathrm{C}$, then stored in refrigerator at $4-6^{\circ} \mathrm{C}$ for later use. In order to maintain the activity of the microorganism, it is important to replacing it every 3 weeks. After that, one or two loop of activated strains was inoculated into $30 \mathrm{~mL}$ of seed medium containing $10 \mathrm{~g} \mathrm{~L}^{-1}$ peptone, $5 \mathrm{~g} \mathrm{~L}^{-}$ ${ }^{1}$ yeast extract, and $10 \mathrm{~g} \mathrm{~L}^{-1} \mathrm{NaCl}$ in a $300 \mathrm{~mL}$ conical flask, and aerobically incubated at $37 \pm 0.5^{\circ} \mathrm{C}$ for $12 \mathrm{~h}$ in a water bath rotary shaker at a speed $180 \mathrm{rpm}$. Finally, the seed culture medium with the strains $(4-14 \mathrm{~mL})$ was then transferred to a $300 \mathrm{~mL}$ conical flask containing $50 \mathrm{~mL}$ of sterilized MSGW medium (the MSGW was diluted 1-10 folds), then the conical flask was placed in a water bath rotary shaker $\left(37 \pm 0.5^{\circ} \mathrm{C}, 180\right.$ $\mathrm{rpm})$ for $48 \mathrm{~h}$. All the mediums were sterilized in an autoclave (SHENAN, China) at $121^{\circ} \mathrm{C}$ and under $0.1 \mathrm{MPa}$ pressures for $20 \mathrm{~min}$ prior to inoculation. All the batch experiments were carried out in triplicate.

\section{Separation, Purification, and Quantification of $\gamma-P G A$}

Gamma PGA was separated and purified by the precipitation method. According to the method described by Ashiuchi et al. ${ }^{[12]}, \gamma$-PGA was hydrolyzed by $6 \mathrm{M} \mathrm{HCl}$ at 
$110^{\circ} \mathrm{C}$ for $24 \mathrm{~h}$, and the glutamate monomers generated were analyzed by the colorimetric method ${ }^{[13]}$.

\section{Coagulation Tests for Culture Supernatant and Crude $\gamma$ - $P G A$}

The fermentation broth was centrifuged. Culture supernatant was obtained besides the biomass. Then crude $\gamma$ PGA was separated from the culture supernatant by the precipitation method. All coagulation tests were carried out using a six-unit stirring apparatus (DC-506, Shanghai, China) at room temperature $\left(25 \pm 3^{\circ} \mathrm{C}\right)$. The preparation of Kaolin synthetic suspension (100NTU, $\mathrm{pH}=7.47)$, active red synthetic dye wastewater $\left(100 \mathrm{mg} \mathrm{L}^{-1}, \mathrm{pH}=8.36\right)$ and coagulation tests procedures were performed as described in literature ${ }^{[14]}$. The culture supernatant and crude $\gamma$-PGA were pre-determined and prepared at a certain concentration (1 $\mathrm{mg} \cdot \mathrm{mL}^{-1}$ for turbidity removal and $10 \mathrm{mg} \cdot \mathrm{mL}^{-1}$ for active red removal) before being added to the test water.

\section{RESUlTS AND DisCUSSION}

\section{A. Influence of Initial MSGW Concentration on Biomass, $O D$ (660) and $\gamma$-PGA Production}

The growth of the microorganism as well as $\gamma$-PGA production was affected by the nutrients concentration in the medium. The microorganism biomass (indicated by dry weight), cell OD (660) and $\gamma$-PGA production of $B$. subtilis 168 cultivated in original MSGW with different dilution fold were investigated and presented in Figure I. Comparing the dilutions from 2-10 folds, the growth of B. subtilis 168 increased with the increasing of MSGW concentration. The microorganism cultivated in the 2-fold diluted MSGW obtained the maximum biomass concentration [OD (660)] and biomass productivity. However, the maximum $\gamma$-PGA production was obtained when the MSGW concentration was 4-fold diluted. The results indicated that nutrients were insufficient for the microorganism growth in low concentration of MSGW. But too high concentration of $\mathrm{SO}_{4}{ }^{2-}$ ion or other contaminants in raw MSGW without dilution would inhibit the microorganism growth and $\gamma$-PGA production. In previous studies, sulfate radical had been proved inhibiting microorganism growth in biological treatment of wastewater. The effect of sulfates concentration on the anaerobic digestion process was investigated and the experimental results indicated that the digestion system would be inhibited severely when the concentration of $\mathrm{SO}_{4}{ }^{2-}$ was $4000 \mathrm{mg} \mathrm{L}^{-1}$. Compared with the value, sulfate concentration (15.26 $\left.\mathrm{g} \mathrm{L}^{-1}\right)$ in raw MSGW was too high for the growth of microorganisms. Therefore, the maximum $\gamma$-PGA production was obtained in 4-fold diluted MSGW, in which sulfate concentration was diluted less than $4000 \mathrm{mg} \mathrm{L}^{-1}$.

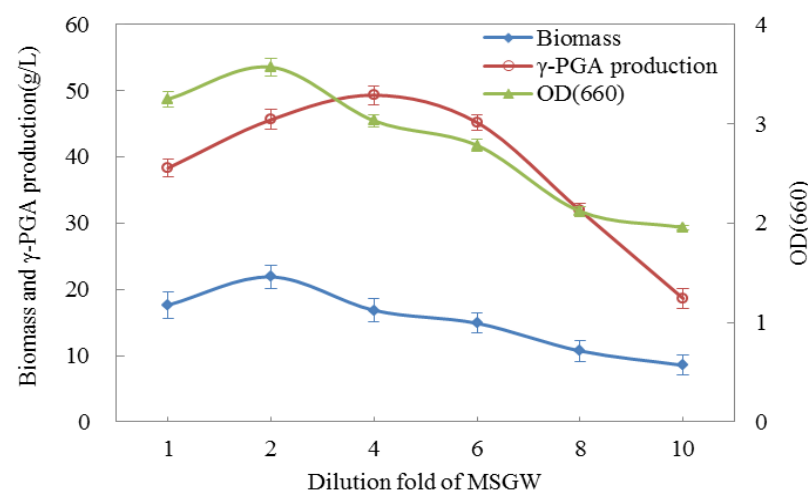

FIGURE I. EFFECTS OF INITIAL MSGW CONCENTRATION ON BIOMASS, OD (660), AND Г-PGA PRODUCTION

\section{B. Influence of Initial Culture $\mathrm{pH}$ on Biomass, $O D$ (660) and $\gamma$-PGA Production}

The initial $\mathrm{pH}$ of culture broth had a critical effect on $\gamma$ PGA accumulation during primary anabolic growth. In order to find an appropriate initial $\mathrm{pH}$ value for the growth of $B$. subtilis 168 in MSGW, different initial culture $\mathrm{pH}(3-8)$ values were chosen in the experiments. Other culturing conditions were as follows: 4-fold diluted MSGW, inoculation volume 10 $\mathrm{mL}$, temperature of $37 \pm 0.5{ }^{\circ} \mathrm{C}$, rotation at the speed of 180 $\mathrm{rpm}$, for $48 \mathrm{~h}$ of cultivation.

Figure II showed the effects of initial culture $\mathrm{pH}$ on biomass, cell OD (660) and $\gamma$-PGA production. It was observed that the three indicators [biomass, cell OD (660) and $\gamma$-PGA production] had the similar trend at $\mathrm{pH}$ 3-8 (increase at $\mathrm{pH} 3-6$, then decrease at $\mathrm{pH} 7-8$ ), and reached a satisfactory combination with values of $16.85 \pm 1.55 \mathrm{~g} \mathrm{~L}^{-1}, 3.031 \pm 0.02$, and $49.33 \pm 1.21 \mathrm{~g} \mathrm{~L}^{-1}$, respectively at $\mathrm{pH}$ 6.0. It was shown that $\mathrm{pH}$ is a significant factor that influences the physiology of a microorganism by affecting nutrient solubility and uptake, enzyme activity, cell membrane morphology, by-product formation and oxidative-reductive reactions. Most studies on fermentative production of $\gamma$-PGA were carried out at $\mathrm{pH} 6.0$ 7.0. It was found in this research that the final $\mathrm{pH}$ of the MSGW fermentation broth reached 9.35 (initial culture $\mathrm{pH}$ 7.0), which is negative to the growth of $B$. subtilis 168 . Therefore, a relative low initial culture $\mathrm{pH} 6.0$ was conducive to the microorganism growth and $\gamma$-PGA production.

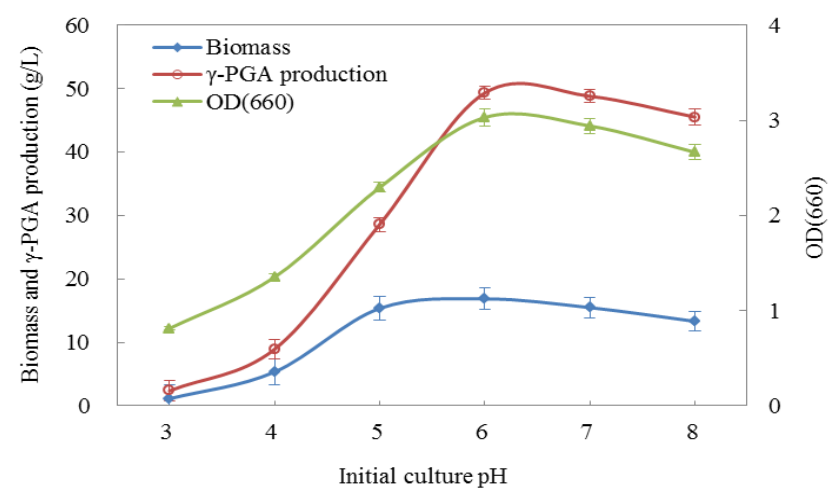

FIGURE II. EFFECTS OF INITIAL CULTURE PH ON BIOMASS, OD (660), AND $\Gamma$-PGA PRODUCTION 


\section{Influences of Inoculation Concentration on Biomass, OD (660) and $\gamma$-PGA Production}

Microbial $\gamma$-PGA production was profoundly related to the inoculation concentration, which is the main factor for $\gamma$-PGA accumulation by $B$. subtilis 168 using MSGW. The following conditions were adopted in this study: 4-fold diluted MSGW, inoculation volumes $4-14 \mathrm{~mL}$, temperature of $37 \pm 0.5{ }^{\circ} \mathrm{C}$, rotation speed at $180 \mathrm{rpm}$, initial culture $\mathrm{pH} 6.0$, and $48 \mathrm{~h}$ of cultivation. The effects of inoculation concentration on biomass, cell OD (660), and $\gamma$-PGA production were shown in Figure III. It could be seen that both biomass and cell OD (660) went up as the inoculation volume increased from 4-10 mL, and reached a steady when the inoculation volume exceeded $10 \mathrm{~mL}$. At the same time, $\gamma$-PGA production increased in the beginning, then decreased with the increase of inoculation volume. The maximum $\gamma$-PGA production of $49.33 \pm 1.21 \mathrm{~g} \mathrm{~L}^{-}$ 1 was obtained at an inoculation volume of $10 \mathrm{~mL}$. As indicated in Figure III, too small or too large inoculation quantity was not favorable for $\gamma$-PGA production, because a low inoculation concentration could promote cell growth vigorously using rich nutrition and affect the synthesis of $\gamma$ PGA. Meanwhile high inoculation concentration would lead to insufficient of nutrition. The nutrition in fermentation medium was exhausted by a mass of bacteria, resulting in a hungry condition of cells during the period of $\gamma$-PGA accumulation, and then affecting $\gamma$-PGA production.

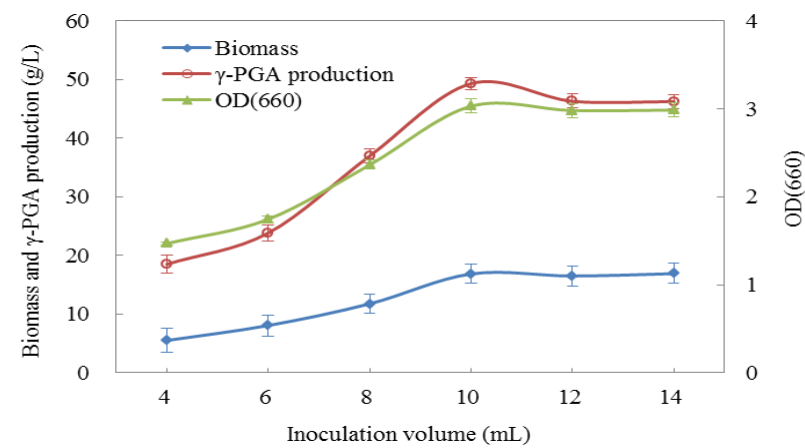

FIGURE III. EFFECTS OF INOCULATION CONCENTRATION ON BIOMASS, OD (660), AND Г-PGA PRODUCTION

\section{Influence of Cultivation Time on Biomass, $O D$ (660) and $\gamma$-PGA Production}

Gamma PGA production showed a significant difference at different growth stages of microorganism. The time course of biomass, cell OD (660) and $\gamma$-PGA production by $B$. subtilis 168 was investigated as shown in Figure IV. The curve of $\gamma$ PGA production showed three stages. Firstly, a slightly rising stage occurred from 0 to $18 \mathrm{~h}$, because microorganism could adapt to the MSGW medium. Secondly, a rapid increasing stage occurred from 18 to $48 \mathrm{~h}$ when the microorganism cell concentration reached to a higher level. Finally, a stable stage was observed from 48 to $72 \mathrm{~h}$. The tendency of microorganism growth with an earlier rapid increasing stage (12-24 h) was similar to that of $\gamma$-PGA production. As illustrated in Figure IV, $\gamma$-PGA production increased sharply and reached the maximum value of $49.33 \pm 1.21 \mathrm{~g} \mathrm{~L}^{-1}$ when cultivation time in MSGW reached $48 \mathrm{~h}$.

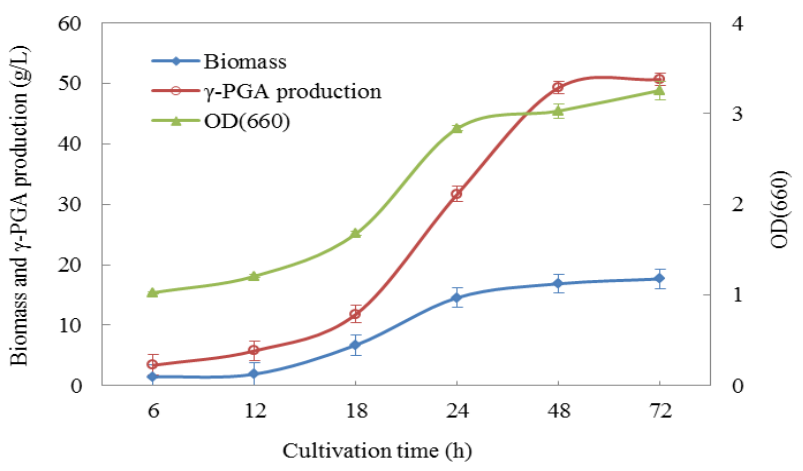

FIGURE IV. EFFECTS OF CULTIVATION TIME ON BIOMASS, OD (660), AND Г-PGA PRODUCTION

\section{E. Flocculation Performance of Culture Supernatant and Crude $\gamma-P G A$}

A series of jar tests was carried out to test the coagulation efficiencies of culture supernatant and crude $\gamma$-PGA on turbidity and color removal (Figure V). It was obvious that crude $\gamma$-PGA performed better than culture supernatant in coagulation, especially for active red removal. Residual turbidity decreased to $25.74 \pm 1.71 \mathrm{NTU}$ and $19.77 \pm 1.56$ NTU when coagulants dosages were $6 \mathrm{mg} \mathrm{L}^{-1}$ for culture supernatant and crude $\gamma$-PGA, respectively. The color removal efficiency of culture supernatant increased gradually with increasing dosages at $20-50 \mathrm{mg} \mathrm{L}^{-1}$, and then the efficiency declined as the dosages increased further, which was due to the color of brown for culture supernatant. Meanwhile, The color removal efficiency of crude $\gamma$-PGA increased with the increasing dosages and reached a stable stage achieved about $55 \%$ color removal efficiency at the dosage of $70 \mathrm{mg} \mathrm{L}^{-1}$.
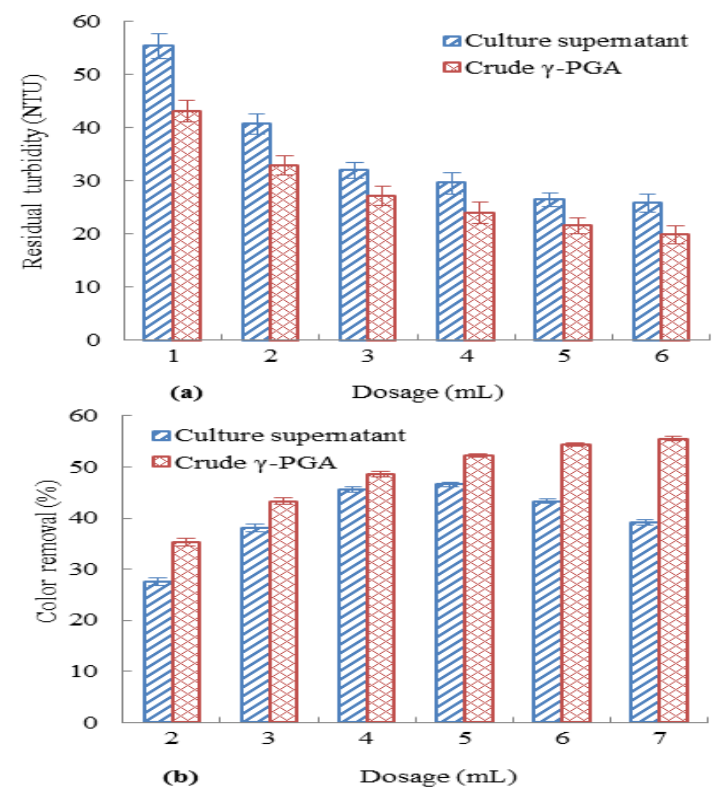

FIGURE V. COAGULATION PERFORMANCE OF CULTURE

SUPERNATANT AND CRUDE $\Gamma$-PGA FOR (A) TURBIDITY AND (B) COLOR REMOVAL ( $\Gamma$-PGA CONCENTRATIONS WERE L MG'ML-1 AND 10 MG'ML-1 FOR TURBIDITY AND ACTIVE RED REMOVAL, RESPECTIVELY). 
The experiments results indicated that the crude $\gamma$-PGA produced by $B$. subtilis 168 had certain coagulation efficiency for both Kaolin synthetic suspension and active red synthetic dye wastewater. Flocculating activity of cross-linked $\gamma$-PGA against Kaolin suspension and synergistic effects of cations were investigated previously. Trivalent cations showed a synergistic effect for $\gamma$-PGA coagulation performance in the research. Therefore, it is worthy of further study to optimize the coagulation conditions and composite with cationic coagulants for improve the coagulation efficiency of $\gamma$-PGA.

\section{CONCLUSION}

The present findings suggested that the MSGW was an ideal medium for $B$. subtilis cultivation to produce $\gamma$-PGA. Single-factor experiments showed that B. subtilis growth and $\gamma$-PGA production were affected by cultivation conditions such as initial MSGW concentration, initial culture broth $\mathrm{pH}$, inoculation concentration, and cultivation time. Simultaneously, results of coagulation tests showed that the turbidity and active red removal efficiency of crude $\gamma$-PGA was about $80 \%$ and $55 \%$, respectively.

\section{ACKNOWLEDGMENT}

This research was supported by the Research Subjects (YKTD201602 and 2018KY009) of Shandong Academy of Governance.

\section{REFERENCES}

[1] More T.T., Yadav J.S.S., Yan S., Tyagi R.D., Surampalli R.Y., 2014. Extracellular polymeric substances of bacteria and their potential environmental applications. J. Environ. Manage. 144, 1-25.

[2] Bajaj I., Singhal R., 2011. Poly (glutamic acid)-An emerging biopolymer of commercial interest. Bioresour. Technol, 102, 5551-5561.

[3] Taniguchi M., Kato K., Shimauchi A., Ping X., Fujita K., Tanaka T., et al., 2005a. Physicochemical Properties of Cross-linked Poly- $\gamma$-Glutamic Acid and Its Flocculating Activity against Kaolin Suspension. J. Biosci. Bioeng. 99, 2, 130-135.

[4] Shih I.L., Van Y.T., 2001. The production of poly- $(\gamma$-glutamic acid $)$ from microorganisms and its various applications. Bioresour. Technol. $79,207-225$.

[5] Kubota H., Matsumoto T., Uotani K., Takebe H., Satoh A., Tanaka T., and Taniguchi M., 1993. Production of poly ( $\gamma$-glutamic acid) by Bacillus subtilis F-2-01. Biosci. Biotech. Biochem. 57, 1212-1213.

[6] Tanaka T., Fujita K., Takenishi S., andTaniguchi M., 1997. Existence of an optically heterogeneous peptide unit in poly ( $\gamma$-glutamic acid) produced by Bacillus subtilis. J. Ferment. Bioeng. 84, 361-364

[7] Taniguchi M., Kato K., Shimauchi A., Ping X., Nakayama H., Fujita K., et al., 2005b. Proposals for Wastewater Treatment by Applying Flocculating Activity of Cross-linked Poly- $\gamma$-Glutamic Acid. J. Biosci. Bioeng. 99, 3, 245-251.

[8] Xu H., Jiang M., Li H., Lu D., Yang, P., 2005. Efficient production of poly $(\gamma$-glutamic acid) by newly isolated Bacillus subtilis NX-2. Process Biochem. 40, 519-523.

[9] Salehizadeh H., Yan N., 2014. Recent advances in extracellular biopolymer flocculants. Biotech. Adv. 32, 1506-1522.

[10] Jia C, Kang R, Zhang Y, Cong W, Cai Z, 2007. Synergic treatment for monosodium glutamate wastewater by Sccharomyces cervisiaeand Coriolus versicolor. Bioresour Technol. 98: 967-970.

[11] Singh S., Rekha P. D., Arun A. B., Hameed A., Singh S., Shen F-T., et al., 2011. Glutamate wastewater as a culture medium for Azospirillum rugosum production and its impact on plant growth. Biol. Fertil. Soils, 47: 419-426.
[12] Ashiuchi, M., Tani, K., Soda, K., and Misono, H., 1998. Properties of glutamate racemase from Bacillus subtilis IFO 3336 producing polygamma-glutamate. J. Biochem. 123, 1156-1163.

[13] Wang A., Wang L.L., Yi H. Zhao Z.H., 2005. Research of determination of glutamic acid by colorimetry. Chin. Condiment, 8, 50-52.

[14] Zhang YL, Li SP, Wang XG, Ma XL, Wang WR, Li XM, 2015. Synthesis, purification and characterization of polyaluminum ferric chloride (PAFC) with high $(\mathrm{Al}+\mathrm{Fe}) \mathrm{b}$ content. Sep. Purif. Technol. 146, 311-316. 